\title{
Letter
}

Arq Neuropsiquiatr 2010;68(1):135-136

\section{Valproic acid-induced pancreatitis in an adult}

\author{
Bruno Lopes dos Santos ${ }^{1}$, Regina Maria França Fernandes², \\ Fábio Fernandes Neves ${ }^{3}$
}

Idiosyncratic reactions to drugs are adverse effects not straightly related with pharmacodynamic mechanisms of the drug and they can take place on unpredictable way by abnormal interaction between the drug and the organism, usually mediated by immunologic or cytotoxic effects triggered by the drug or its metabolites ${ }^{1}$. Even being responsible for $6-10 \%$ of all the adverse reactions to drugs, the idiosyncratic effects can be important sources of morbidity and mortality, mainly in children ${ }^{1}$. The anti-epileptic drugs (AED) also can cause adverse effects by these mechanisms, which impairs the seizure control and obliges the physician to use second line drugs. A study in epileptic patients showed that 10 to $27 \%$ stopped their first treatment with AED on account of the adverse effects, being several of them idiosyncratic $^{1}$. Valproic acid (VPA) is a carboxylic acid used as anti-epileptic in idiopathic and symptomatic generalized epilepsies and in some cases of symptomatic focal epilepsies, as well as for trigeminal neuralgia, migraine and bipolar disorders ${ }^{3}$. Its mechanism is unknown, however it is probably associated with the metabolism of the neurotransmitter GABA. The toxic effects it provokes can be dose-dependent or idiosyncratic. There are several VPA-related idiosyncrasies, being the most noteworthy alopecia, bone marrow aplasia, immune-mediated hepatotoxicity and pancreatitis ${ }^{1}$. The acute pancreatitis is a disease of several etiologies, sometimes caused by use of determined drugs. The pancreatitis provoked by VPA is a rare entity, with estimated incidence of $1: 40000^{2}$, occurring mainly during the first year of treatment or after increase in the dose, with higher incidence in young individuals, in polytherapy (mainly with carbamazepine, phenytoin, phenobarbital and some benzodiazepines), with chronic encephalopathies and in dialysis treatment ${ }^{1,2}$. The supposed pathogenic mechanism is by direct toxic effect of free radicals in the membranes of the pancreatic cells ${ }^{2,3,5,6}$. The onset can be a slight asymptomatic hyperamylasemia up to a fatal necrohemorragic pancreatitis ${ }^{4}$, and the mortality varies from 17 to $20 \%$, with many complications in the non-lethal cases (pseudocysts, infections, septic shock, chronic pancreatitis, endocrine pancreatic insufficiency) ${ }^{2}$. The treatment is based on the immediate withdrawal of the drug, general clinical support and specific treatment of the possible complications.

We present the case of a patient who, in less than 2 months of treatment with appropriate dose of VPA, evolved to pancreatitis.

\section{CASE}

A male 34 years-old, white, resident at Ribeirão Preto, tattooist, single, with a past history of depressive episode, began to have complex partial seizures by 25 years of age, in increasing frequency. After the diagnosis of focal epilepsy, he was put on VPA, in dose of $16.5 \mathrm{mg} / \mathrm{kg} /$ day, increasing up to $25 \mathrm{mg} / \mathrm{kg} /$ day after 25 days as the initial dose. After such increase in daily dose, he felt a mild epigastric pain, improved by symptomatic medicines, however on a progressive pattern. After 15 days using VPA at $25 \mathrm{mg} / \mathrm{kg} /$ day,
Bruno Lopes dos Santos Rua Albert Einstein 1360 14051-110 Ribeirão Preto SP - Brasil E-mail: alucardtzimisce@hotmail.com

Received 10 April 2009 Received in final form 11 April 2009 Accepted 16 September 2009

\section{PANCREATITE AGUDA EM ADULTO INDUZIDA PELO ÁCIDO VALPRÓICO}

Ribeirão Preto School of Medicine, University of São Paulo, São Paulo SP, Brazil: 'Physician Resident in Neurology, Department of Neurosciences and Behaviour Sciences; ${ }^{2}$ Neurologist and Associated Professor, Department of Neurosciences and Behaviour Sciences; ${ }^{3}$ Emergencist Physician, Departament of Internal Medicine. 
there was worsening of epigastric pain with became very intense, enhancing after food, irradiating to the dorsal area of trunk, associated with vomiting and anorexia. He was admitted in an emergency room, with serum amylase of $1682 \mathrm{UI} / \mathrm{L}$, being transferred to our service under the suspicion of acute pancreatitis. There was no history of ethylic abusive drinking, abdominal traumas nor recent infectious disorders. On physical examination, he was afebrile, normal vital signs and diffuse abdominal pain, without signs of peritonitis. Laboratorial workup showed leukocytosis, serum amylase of $1743 \mathrm{UI} / \mathrm{L}$, lipase $375 \mathrm{UI} / \mathrm{L}$, normal arterial blood gas analysis, without scoring in the Ranson's severity criteria in the admission and APACHE II of 4 points. Clinical measures for acute pancreatitis were provided; he was put off VPA and started on carbamazepine. On abdominal ultrasound, showed no alteration in the biliary tract, with some increase in pancreatic volume and small ascitis. Abdominal CT scan showed a diffuse increase in pancreas volume, presence of per pancreatic liquid, slight ascitis and a small pleural effusion on the left, classified as edematous acute pancreatitis Balthazar B. The lipid profile was normal, with low serum VPA level and normal plasma ammonia. HIV and hepatitis serologic tests were negative. The patient went on well, without recurrence of the abdominal pain with fasting, with no scoring in Ranson's criteria after 48 hours. Oral diet was gradually reintroduced with good acceptance and no worsening of the symptoms. He was discharged in the 6th day of hospitalization, with serum amylase of 341UI/L.

\section{DISCUSSION}

The first cases of acute pancreatitis associated to VPA were reported in 1979, by Bataladen et al. ${ }^{7}$ and Camfield et al. ${ }^{8}$, with several sporadic cases being published subsequently. There are 2 cases described in the Latin America, all in Brazil, the first one in 1986, by Tannhauser Barros et $\mathrm{al}^{7}{ }^{7}$, and the other in 1998 by Munhoz et al. ${ }^{8}$. Most of the reported cases happened in children ${ }^{2}$, correspond- ing to $13 \%$ of all cases of acute pancreatitis of childhood. From the first description, some literature reviews have been done $e^{2,4,9,10}$, with 106 cases described until the moment of the finishing of this report, however there are doubts about these numbers ${ }^{10}$.

In our case, the age of the patient is compatible with the most affected age group in adults, but the patient was not using polytherapy and the disease developed in only 40 days after the beginning of the drug (as seen by Biour et al. ${ }^{9}$, there is a case with 1 day of use of VPA), in the appropriate dose $(25 \mathrm{mg} / \mathrm{kg} /$ day $)$, with ascending serum level $(18,52 \mathrm{mg} / \mathrm{dL})$, the lowest level of all reported in the literature, reinforcing the idiosyncratic nature of this adverse reaction ${ }^{1}$. It is expected that this complication related to a widely used drug might have an incidence much higher than reported in the literature, because of under notification, and physicians who prescribe AED on a daily basis, and should be aware in order to recognize the first signs of this disorder.

\section{REFERENCES}

1. Zaccara G, Franciotta D, Perucca E. Idiosyncratic adverse reactions to antiepileptic drugs. Epilepsia 2007;48:1223-1244.

2. Gerstner T, Busing D, Bell N, et al. Valproic acid-induced pancreatitis: 16 new cases and a review of the literature. J Gastroenterol 2007;42:39-48.

3. Genton P, Gelisse P. Valproic acid. Adverse effects. In: Levy RH, Mattson RH, Meldrum BS, Perucca E (Eds). Antiepileptic drugs. $5^{\text {th }}$ Ed. Philadelphia: Lippincott William \& Wilkins 2002:838-851.

4. Binek J, Hany A, Heer M. Valproic-acid-induced pancreatitis: case report and review of the literature. J Clin Gastroenterol 1991;13:690-693.

5. Bataladen PB, Van Dyne BJ, Cloyd J. Pancreatitis associated with valproic acid therapy. Pediatrics 1979; 64:520-522.

6. Camfield PR, Bagnell P, Camfield CS. Pancreatitis due to valproate acid. Lancet 1979;1:1198-1199.

7. Tannhauser Barros HM, Guardião Barros EJ. Pancreatite aguda associada ao uso de valproato de sódio. Rev Assoc Med Brasil 1986;32:33-34.

8. Munhoz RP, Santos ML, Hernandez-Fustes OJ. Fatal necrohemorrhagic pancreatitis related to sodium valproate: case report. Arq Neuropsiquiatr 2001;59: 821-823.

9. Biour M, Daoud H, Ben Salem C. Drug-induced pancreatitis: second edition of the bibliographic database of pancreatitis related to drugs. Gastroenterol Clin Biol 2005;29:353-359.

10. Ben Salem C, Biour M, Hmouda H, Bouraoui A. Valproic acid-induced pancreatitis. J Gastroenterol 2007;42:598-599. 